\title{
Domestic violence: safe and compassionate consultations
}

Dowrick, A, Sohal, A, Kelly, M, Griffiths, C, Feder, G

Up to one third of women presenting in general practice have experienced domestic violence and abuse (DVA) in a current or past relationship. It is associated with a wide range of commonly seen medical symptoms. Clinicians sometimes lack confidence in asking about abuse because of concerns about time, patient safety, how to respond appropriately, and limited knowledge of support services. Addressing DVA can lead to significant improvements in patient health and well-being, as well as rewarding consultations for practitioners. Drawing on research with GPs and patients, this article offers advice about delivering safe and compassionate consultations about DVA.

\section{The GP curriculum and consultations}

\section{Professional module 2.01: The GP consultation in practice states that}

- As a general practitioner you must show a commitment to patient-centred medicine, displaying a non-judgmental attitude, promoting equality and valuing diversity

- As a general practitioner you must manage complexity, uncertainty and continuity of care within the time-restricted setting of a consultation

\section{Clinical module 3.04: Care of children and young people requires GPs to:}

- Recognise the needs of children of parents with substance or alcohol misuse, mental health or domestic violence and abuse problems

- Demonstrate an understanding of the welfare of the unborn baby by:

- Being aware of the impact of parental problems including domestic violence and abuse, substance and alcohol misuse and mental health problems

- Being able to recognise the symptoms and presentations of such problems and to make a sensitive enquiry if concerned

\section{Clinical module 3.06: Women's health requires GPs to:}

- Become sensitive to; domestic violence, depression and alcoholism, which can all present differently in women and may be interlinked.

- Recognise the prevalence of domestic violence and question sensitively where this may be an issue

- Maintain patient records that are accurate, facilitate continuity of care and 
respect the patient's confidentiality

- Provide information to patients on possible local support services, referral services, networks and groups for women

\section{The consultation and domestic violence and abuse}

The consultation is the cornerstone of general practice (Denness, 2013). It is where suffering can be acknowledged and hope can be offered (Dowrick, 2017; Heath, 1995)

The pressure to complete a consultation in 10 minutes can lead to a prioritisation of more obvious complaints, or discussions required to meet targets, over exploratory discussion of patient experience. It can also lead to what Balint (1957) referred to as the 'collusion of silence', where some topics are considered out of bounds for either or both of patient and doctor.

DVA is a common problem, with a lifetime population prevalence of 1 in 4 women (Garcia-Moreno, Jansen, \& Ellsberg, 2006). In general practice the lifetime prevalence is higher, and can be as much as 1 in 3 (Feder et al., 2009). In one survey of 12 general practices, 17\% of women consulting doctors and nurses reported experiencing physical abuse within the previous 12 months (Richardson et al., 2002). Despite this, it is a topic many practitioners feel fearful or nervous to approach (Yeung, Chowdhury, Malpass, \& Feder, 2012).

This article offers advice about how to safely and effectively address domestic violence and abuse in a consultation. Points are illustrated with real cases drawn from qualitative interviews with GPs and patients undertaken as part of an evaluation of the DVA training and support programme IRIS. More information can be found in Box 1. 
Insert box 1 here 


\section{Domestic violence and abuse as a health issue}

Over the past 20 years a strong evidence base has developed demonstrating links between common health problems and DVA (NICE, 2016). The definition of DVA is provided in Box 2. Current or historic DVA may lie behind a range of presentations such as pain, headaches, tiredness, low mood, anxiety, gastrointestinal complaints, and gynaecological problems (Feder \& Howarth, 2014; Valpied \& Hegarty, 2015). DVA during pregnancy is associated with negative health outcomes for both mother and foetus(Finnbogadóttir, Dykes, \& Wann-Hansson, 2016). DVA has long-lasting effects on health even when there is no ongoing abuse. A full list of potential associations can be found in Table 1.

\section{Insert Table 1 and box 2 here}

DVA is ubiquitous across all ethnicities, ages, classes, religions, sexualities and genders. However, there are important differences between genders. While men and women are both affected by domestic abuse, prevalence is higher among women. In the UK, $27 \%$ of women and $13 \%$ of men have experienced some form of domestic abuse. The impact on women's health is more severe and abuse is more lethal for women (Hester et al., 2015).

Globally, there has been a proliferation of studies into the role that can be played by primary care professionals in responding to domestic abuse (García-Moreno et al., 2014). Primary care professionals are trusted by survivors of abuse (Malpass et al., 2014). Women report wanting to be asked about abuse in encounters with primary care professionals (Taket et al., 2003). Women and men want responses from health care professionals that are non-judgmental, individually tailored and show understanding of the complexity of partner violence (Feder, Hutson, Ramsay, \& Taket, 2006) but men may exhibit different help-seeking behaviour (Williamson et al., 2015). 
General practice is a safe, locally accessible place to talk about abuse. Despite being controlled by a partner, patients can bring legitimate health concerns to their GP. It is an opportunity to be alone, which may allow them to talk about current or past abuse. Moreover, as gatekeepers of other support services, GPs are well placed to offer referral to specialist domestic violence support services and can offer long term continuity of care that is challenging in other services. The following sections will offer pragmatic advice about how to approach domestic violence in a consultation, with cases studies from GPs and patients.

\section{Addressing domestic violence}

\section{Not just a single consultation}

There are two important components in a disclosure of abuse: trust and safety. Rapport is an important element of a disclosure and it may take several appointments meetings for a patient to feel trusting enough to disclose. If there isn't time to address it in one consultation you can invite them back, safely making a note to talk about it next time. Meeting without the presence of the perpetrator is also important for a disclosure. Arranging a follow-up appointment with a patient on their own can be an opportunity to begin a discussion.

A disclosure of domestic abuse is not a one-off act. It is part of a process of change in which a patient will recognise their relationship as problematic and feel able to takes steps to address it. As such, discussions about domestic violence need not be contained within a single consultation and can be spread out across a number of meetings.

Asking about abuse demonstrates to a patient that it is a legitimate topic of discussion with a GP, even if they are not ready to share their experiences in that moment. Having materials in the practice about domestic violence, such as helpline numbers or posters, help promote a safe environment for disclosure. 


\section{Case study 1.}

Denise rarely expected a disclosure of abuse the first time she met a patient. 'They're pretty good at sussing you out, patients. I think that's why it often takes a few attendances or questioning before they disclose, they're sort of checking you out. They might come back and you think, 'Well, I'm not sure why you're here because we discussed this last week!', or sometimes they come with a friend or family member and they're not the ones consulting, but then they'll pitch up a week or so later with a related problem. I think patients choose what they tell GPs and who to tell. '

\section{Finding the right moment to ask}

The art of consulting involves addressing both the obvious and subtle issues that are brought by a patient. Asking about domestic violence can seem daunting because, if the patient doesn't raise it, there isn't always an obvious moment to ask.

There is no evidence that screening for domestic violence in primary care is more effective than clinical enquiry or case finding, but its hidden nature means doctors should have a low threshold for asking (Feder et al., 2009). A patient may spontaneously disclose abuse, however the majority of women who have experienced abuse report wanting to be asked about it. If a patient is on their own, there are three situations that offer safe opportunities to raise the topic:

- Exploring symptoms

- Responding to cues

- Using information provided by other agencies.

In order to raise awareness of situations in which it might be appropriate to ask about DVA, practices can upload the validated HARK template onto their computer systems. This offers prompts to ask about DVA in line with the 
symptoms presented by the patient. Clinicians report that it acts as a useful reminder to consider DVA as part of care. More details can be found in Box 3 .

\section{Insert box 3 here}

\section{Explore the issue brought to the consultation}

As detailed in Table 1, domestic violence is associated with a wide range of common presentations in general practice, e.g. mental health, gynaecological problems, headaches, irritable bowel syndrome. Each clinician should phrase a question about DVA in a way that fits their consultation style. Example questions include:

- Some women have these symptoms/injuries when they are at risk of abuse. Are you afraid of anyone at home? Does anyone try to control you or what you do?

- How is your relationship with your husband/partner/family? Has someone hurt you? Do you feel safe?

- Sometimes people with chronic pain have a lot of pain or tension in their lives that is reflected in their bodies. Might that be happening to you? Are you ever afraid of, humiliated or hurt by anyone?

- Sometimes people with depression/low self esteem have experienced major life events that cause this and can explain why they feel so low. Living in an abusive relationship can cause this. Might that be happening to you? 


\section{Case study 2.}

Patient case study

Shazia was in an abusive relationship and felt very depressed and hopeless. She went to her GP and received a referral into domestic violence support services.

I was really depressed, and just felt lost, the only thing that comes to my mind was to go to the doctor and ask for some anti-depressant medication. Then when I met her, she said 'you have lots of things going on, so it's not something that I can help with antidepressant medication'. I was suffering from financial problems, living in a violent relationship, so she said 'It might help to refer you for something where they can help you with your housing issues, your financial issues and your emotional issues' and she referred me to some support services.

\section{Explore cues}

The Cambridge-Calgary (1998) consultation model highlighted the importance for looking out for verbal and non-verbal cues in what a patient is discussing which might suggest other issues.

As well as taking note of agitation or tearfulness, careful listening to the story presented by the patient can reveal hints towards hidden concerns. Following Moulton's (2007) idea of 'golden minutes', allowing a patient the opportunity to present their issue uninterrupted at the start of the consultation can reveal opportunities to raise the issue of domestic abuse.

\section{Case study 3.}


Angela unexpectedly discovered abuse when listening to her patient talk about bad breath.

She just started talking about her breath, actually, it was bad breath. And while she was talking I was thinking, 'Wow, this is having a massive impact on her life this is more than about bad breath', and suddenly you get this flash of, 'Oh, I wonder what's going on!?' So then I asked her, "How is your relationship?" and her partner had made a comment about her breath a year ago and it had all spiralled, and then you get into the questions of he's very controlling, not physically violent, but etc., etc. And I could easily have gone through consultation, I can't remember if it was about a pain in her elbow or something that was very, very medical, no other issues, and easily she could have just walked out the room again. So it is sometimes just something in the consultation where you think, 'oh, this isn't quite right. Why is she worried about her breath?'

\section{Information provided by another agency}

Domestic abuse may be brought to your attention by another service, such as social services, the Police, or an emergency department.

This provides an opportunity to raise the issue with the patient, for instance by exploring the incident that led to information being shared. You should not assume that other agencies have offered a referral for support services.

\section{Validate response}

Offering a non-judgemental, validating response is one of the most important acts you can do as a health professional to support someone who has experienced domestic abuse. A feature of coercive control is that the perpetrator 
makes the victim feel that the abuse is their fault, that they are worthless and that there is no hope for change.

Affirming the patient's worth is an important contribution towards them feeling able to make changes in their life. Examples of validating responses are provided in Box 4.

\section{Insert box 4 here}

\section{Case study 4.}

Jean was anxious about how her GP might act after her disclosure of abuse, but received an affirming response.

She was really supportive actually, she was almost defensive for me. I came away feeling like 'Yeah, I've done the right thing'. I wasn't sure how it was going to go, because there was a massive stigma attached to it, in my mind. But then the GPS reaction was like 'It's not your fault, and there's things we can do to help you'.

\section{Explore safety}

The majority of cases of DVA that present in general practice will not require an emergency referral, being more akin to chronic conditions. After giving a validating response, you should check the immediate safety of the patient and any children by asking simple questions, such as 'are you safe to go home?' or 'has the violence become more frequent or escalated recently?' If you judge that is unsafe for the patient to return home then you can support them to either urgently contact a specialist DVA service or, if that is not possible, the police. A more detailed risk assessment can be carried out by DVA support services or the police. 


\section{Share the care}

Being aware of the contact details of your local domestic violence support services and how to make a referral will make it easier raise the topic of abuse and to respond to a disclosure. Practical and emotional support can be provided by specialist domestic violence support services. Details of national agencies can be found in box 5 .

Anyone who discloses should be offered a referral to specialist domestic violence support services. All areas offer domestic violence support services, though in some areas government funding is used to offer a dedicated primary care domestic violence service called IRIS that offers a direct referral route from general practice, and has been shown to increase identification of DVA and referral for support (Feder et al., 2011). You should also follow the safeguarding route in your practice for children in families affected by abuse.

There is also some evidence to suggest that trauma-informed psychological support, from practitioners who have a good awareness of the dynamics of power and control within DVA, may be helpful to support the mental health of patients who have experienced abuse (Brierley et al., 2013)

The most effective care for domestic abuse is delivered as part of a team. You can discuss the case with other members of the practice and your practice should also have a safeguarding lead who can offer advice. Discussing the patient with other professionals involved in the patient's care, such as health visiting and midwifery services, may also be helpful.

\section{Record in notes}

Recording discussions about DVA in patient notes is important for other professionals who may be in contact with them, and for building a clearer national and local picture of the prevalence and incidence of abuse. 
However, there are issues with regard to safety because of changes in access to online records, in which the person perpetrating abuse may be able to gain access to a victim's notes.

Feder and Potter (2017) have developed guidance for safely recording DVA:

- Ensure any reference to DVA is not accidentally visible to the perpetrator during appointments. The computer screen showing the medical record should never be seen by third parties.

- Ensure the decision to record the information in the perpetrator's EMR is made with due regard to the associated risks and documented.

- Ensure any reference to DVA in records is redacted if provided to perpetrator unless you are certain it is information the perpetrator already knows.

These are first steps towards safely recording domestic violence. Further information can be found in the RCGP (2017) Safeguarding Adults at Risk of Harm toolkit.

\section{Self-care}

John Berger, in his famous 1967 written portrait of the country doctor John Sassall, reflected:

What is the effect of facing, trying to understand, hoping to overcome the extreme anguish of other persons five or six times a week?

I do not speak now of physical anguish, for that can usually be relieved in a matter of minutes. I speak of the anguish of dying, of loss, of fear, of loneliness, of being desperately beside oneself, of the sense of futility.

His question remains important today. Heath (2012) presents one of the key areas of a GPs work as being a witness to the suffering of others. The increasing 
pressure of this work is leading to burn out becoming a growing issue across the health care profession (Zenasni, Boujut, Woerner, \& Sultan, 2012)

Self-care is essential in order to have the energy to engage in the issue of DVA and to release emotion felt by doing this work. Witnessing someone's story of domestic abuse can elicit a range of reactions from practitioners, including anger, distress and anxiety. It can also connect to personal experiences and deeply held morals.

Neighbour (1986) introduced the notion of housekeeping to consultation skills. He raised the importance of acknowledging and dealing with emotions that arise from one consultation before embarking on the next, to avoid an adverse effect on the next patient interaction. Following Balint (1957), he acknowledged that consultations involve emotion, and that this can be draining.

The issue of having enough time to raise the topic of abuse is often secondary to having the energy to engage in the topic after a busy day of general practice. It is about a quality as well as quantity of time.

\section{Case study 5.}

Nakesh felt more able to ask about abuse when he had the emotional energy to engage with patients.

With domestic violence, there's a moral element to it there, that's perhaps not so much present in other things. Making yourself emotionally available to discuss it isn't necessarily just longer work, it's a different type of work. Every person I've spoken to will say that with a doctor you're not getting the same person at the start of the day as you are at the end. So the point is if you're tired, if you've been speaking to people all day, your emotional reserves as much less at the end of the day, so what you have to offer patients... you just don't have the emotional energy to do it'

Options to address this in relation to domestic violence include: 
- Regular opportunities within practice to discuss complicated cases

- Good relationships with specialist services

- Regular supervision sessions as a trainee

○ Time between consultations or between sessions to address experiences

○ Mindfulness training

○ Balint groups

\section{Conclusion}

Domestic violence and abuse is prevalent among patients who present in general practice, and is linked to a wide range of common health conditions. GPs are in a good position as a trusted professional to create a context to discuss domestic abuse, to compassionately validate experiences and to offer referral to specialist support. Approaching DVA as a long-term chronic condition can help with management of consultation time and style. Self-care is important for ensuring clinicians maintain the emotional capacity to bear witness to suffering and offer hope to survivors of abuse.

\section{Key points}

- Domestic violence is associated with a wide range of common presentations in general practice

- Preparing a context to discuss domestic violence can take place over a number of consultations

- There are opportunities to ask about abuse in relation to the presenting symptom or cues offered by the patient.

- Because of fear and stigma, it may take several instances of being asked about abuse before a disclosure is made.

- Following a disclosure a GP should validate someone's experience, do an immediate safety check and offer a referral to a specialist domestic violence support service and, if safe, record the discussion in the medical record. 
- Consistently providing safe, compassionate and effective care can take an emotional toll on a clinician, and self-care is essential.

\section{Acknowledgement}

This research was funded by the National Institute for Health Research (NIHR)

Collaboration for Leadership in Applied Health Research and Care North Thames at Barts Health NHS Trust. The views expressed are those of the author(s) and not necessarily those of the NHS, the NIHR or the Department of Health

\section{References and further information}

Balint, M. (2000). The doctor, his patient and the illness. Churchill Livingstone: London

Barry, C. A. (2000). Patients' unvoiced agendas in general practice consultations: qualitative study. BMJ, 320(7244), 1246-1250. doi: 10.1136/bmj.320.7244.1246

Berger, J., \& Mohr, J. (1967). A fortunate man : the story of a country doctor. Penguin: London

Brierley, G., Agnew-Davies, R., Bailey, J., Evans, M., Fackrell, M., Ferrari, G., ... Feder, G. S. (2013). Psychological advocacy toward healing (PATH): study protocol for a randomized controlled trial. Trials, 14, 221. http://doi.org/10.1186/1745-6215-14-221

Denness, C. (2013). What are consultation models for? InnovAiT: Education and Inspiration for General Practice, 6(9), 592-599. doi: $10.1177 / 1755738013475436$

Dowrick, C. (2017). Suffering and hope: Helen Lester Memorial Lecture 2016. BJGP Open, BJGP-2016-0584. doi: 10.3399/bjgpopen17X100605 
Feder, G., Davies, R. A., Baird, K., Dunne, D., Eldridge, S., Griffiths, C., ... Sharp, D. (2011). Identification and Referral to Improve Safety (IRIS) of women experiencing domestic violence with a primary care training and support programme: A cluster randomised controlled trial. The Lancet, 378, 17881795. doi: 10.1016/S0140-6736(11)61179-3

Feder G, Howarth E. (2014). The epidemiology of gender based violence in Bewley, S., \& Welch, J. (2014). ABC of domestic and sexual violence. WileyBlackwell: Oxford

Feder, G and Potter, L. (2017) Safeguarding Adults at Risk of Harm Toolkit. Royal College of General Pracitioners: London. Retrieved from:

http://www.rcgp.org.uk/clinical-and-research/toolkits/safeguarding-adults-atrisk-of-harm-toolkit.aspx

Feder, G., Ramsay, J., Dunne, D., Rose, M., Arsene, C., Norman, R., ... Taket, A. (2009). How far does screening women for domestic (partner) violence in different health-care settings meet the UK National Screening Committee criteria for a screening programme? Systematic reviews of nine UK National Screening Committee criteria. Health Technology Assessment, 13(16), iii-iv, xi-xiii, 1-113, 137-347. doi: 10.3310/hta13160

Feder, G. S., Hutson, M., Ramsay, J., \& Taket, A. R. (2006). Women exposed to intimate partner violence: expectations and experiences when they encounter health care professionals: a meta-analysis of qualitative studies. Archives of Internal Medicine, 166(1), 22-37. doi: 10.1001/archinte.166.1.22

Finnbogadóttir, H., Dykes, A.-K., \& Wann-Hansson, C. (2016). Prevalence and incidence of domestic violence during pregnancy and associated risk factors: a longitudinal cohort study in the south of Sweden. BMC Pregnancy and Childbirth, 16(1), 228. http://doi.org/10.1186/s12884-016-1017-6

García-Moreno, C., Hegarty, K., Lucas d’Oliveira, A. F., Koziol-MacLain, J., 
Colombini, M., \& Feder, G. (2014). The health-systems response to violence against women. The Lancet, 385(9977), 1567-1579. doi: 10.1016/S0140$6736(14) 61837-7$

Garcia-Moreno, C., Jansen, H., \& Ellsberg, M. (2006). Prevalence of intimate partner violence: findings from the WHO multi-country study on women's health and domestic violence. The Lancet. Retrieved from http://www.sciencedirect.com/science/article/pii/S0140673606695238

Heath, I. (1995). The mystery of general practice. Nuffield Trust. Retrieved from: https://www.nuffieldtrust.org.uk/research/the-mystery-of-generalpractice

Hester, M., Ferrari, G., Jones, S. K., Williamson, E., Bacchus, L. J., Peters, T. J., \& Feder, G. (2015). Occurrence and impact of negative behaviour, including domestic violence and abuse, in men attending UK primary care health clinics: a cross-sectional survey. BMJ Open, 5(5), e007141. doi: 10.1136/bmjopen-2014-007141

Malpass, A., Sales, K., Johnson, M., Howell, A., Agnew-Davies, R., \& Feder, G. (2014). Women's experiences of referral to a domestic violence advocate in UK primary care settings: a service-user collaborative study. The British Journal of General Practice. 64(620), e151-8. doi: 10.3399/bjgp14X677527

Moulton, L. (2007). The naked consultation : a practical guide to primary care consultation skills. Radcliffe Publishing, Abingdon

NICE. (2016). Quality Standard [QS116]: Domestic violence and abuse. Retrieved from: https://www.nice.org.uk/guidance/qs116

Richardson, J., Coid, J., Petruckevitch, A., Chung, W. S., Moorey, S., \& Feder, G. (2002). Identifying domestic violence: cross sectional study in primary care. BMJ, 324(7332), 274. dooi: 10.1136/bmj.324.7332.274 
RCGP. Professional Module 2.01: The GP Consultation in Practice. Retrieved from: http://www.rcgp.org.uk/training-exams/gp-curriculum-overview/onlinecurriculum/knowing-yourself-and-relating-to-others/2-01-the-gp-consultationin-practice.aspx

RCGP. Clinical module 3.04: Care of children and young people. Retrieved from: http://www.rcgp.org.uk/training-exams/gp-curriculum-overview/onlinecurriculum/caring-for-the-whole-person/3-04-children-and-young-people.aspx

RCGP. Clinical module 3.06: Women's health. Retrieved from:

http://www.rcgp.org.uk/training-exams/gp-curriculum-overview/onlinecurriculum/caring-for-the-whole-person/3-06-womens-health.aspx

Sohal, H., Eldridge, S., \& Feder, G. (2007). The sensitivity and specificity of four questions (HARK) to identify intimate partner violence: a diagnostic accuracy study in general practice. BMC Family Practice, 8, 49. doi: 10.1186/1471-2296-8-49

Taket, A., Nurse, J., Smith, K., Watson, J., Shakespeare, J., Lavis, V., ... Feder, G. (2003). Routinely asking women about domestic violence in health settings. BMJ (Clinical Research Ed.), 327(7416), 673-6. doi: $10.1136 / \mathrm{bmj} .327 .7416 .673$

Valpied, J., \& Hegarty, K. (2015). Intimate partner abuse: identifying, caring for and helping women in healthcare settings. Women's Health (London, England), 11(1), 51-63. doi: 10.2217/whe.14.59

Williamson, E., Jones, S. K., Ferrari, G., Debbonaire, T., Feder, G., \& Hester, M. (2015). Health professionals responding to men for safety (HERMES): feasibility of a general practice training intervention to improve the response to male patients who have experienced or perpetrated domestic 
violence and abuse. Primary Health Care Research \& Development, 16(3), 281-288. http://doi.org/10.1017/S1463423614000358

Yeung, H., Chowdhury, N., Malpass, A., \& Feder, G. S. (2012). Responding to domestic violence in general practice: a qualitative study on perceptions and experiences. International Journal of Family Medicine, 2012, 960523. doi: $10.1155 / 2012 / 960523$

Zenasni, F., Boujut, E., Woerner, A., \& Sultan, S. (2012). Burnout and empathy in primary care: three hypotheses. The British Journal of General Practice 62(600), 346-7. doi: 10.3399/bjgp12X652193

\section{Insert box 5 here}




\section{Box 1. Identification and Referral to Improve Safety (IRIS)}

- IRIS is an evidence based DVA training and support programme

- It consists of training for the practice team, a prompt in the electronic patient record and a direct referral pathway into local specialist DVA support services

- An RCT demonstrated it was successful at increased identification and referral for support (Feder et al., 2011)

- It has been rolled-out in 30 areas of the UK

- Cases in this paper are drawn from the qualitative arm of a mixedmethods evaluation of the implementation of IRIS.

http://www.irisdomesticviolence.org.uk/iris/

\section{Box 2. Cross-government definition of domestic violence}

Any incident or pattern of incidents of controlling, coercive or threatening behaviour, violence or abuse between those aged 16 or over who are or have been intimate partners or family members regardless of gender or sexuality. This can encompass but is not limited to the following types of abuse:

- Psychological

- Physical

- Sexual

- Financial

- Emotional

\section{Controlling behaviour}

Controlling behaviour is a range of acts designed to make a person subordinate and/or dependent by isolating them from sources of support, exploiting their resources and capacities for personal gain, depriving them of the means needed for independence, resistance and escape and regulating their everyday behaviour.

\section{Coercive behaviour}

Coercive behaviour is an act or a pattern of acts of assault, threats, humiliation and intimidation or other abuse that is used to harm, punish, or frighten their victim.

This UK-wide definition from 2013 provided unity across definitions that were previously being used by different government departments. 


\section{BOX 3. HARK}

- HARK is a validated electronic pop-up prompt that can be loaded onto a record management system to appear in the patient medical record (Sohal, Eldridge, \& Feder, 2007).

- It is connected to READ codes that correlate to potential DVA.

- It is a mnemonic that stands for: Humiliate (psychological abuse), Afraid (emotional abuse), Rape (sexual abuse), Kick (physical abuse)

\section{Box 4. Examples of validating responses}

- 'Everybody deserves to feel safe at home'”

- 'You don't deserve to be hit or hurt. It is not your fault'

- 'I am concerned about your safety and wellbeing'

- 'You are not alone. Help is available'

- 'You are not to blame. Abuse is common and happens in all kinds of relationships. It tends to continue'

- 'Abuse can affect your health and that of your children in many ways' 


\section{Box 5. Domestic violence resources}

RCGP e-Learning

The RCGP's Violence Against Women and Children e-learning course enables GPs and other primary care professionals to improve their recognition of and response to patients suffering from violence.

Access the Violence Against Women and Children course

RCGP Safeguarding Adults at Risk of Harm Toolkit

http://www.rcgp.org.uk/clinical-and-research/toolkits/safeguarding-adultsat-risk-of-harm-toolkit.aspx

\section{4-hour National Domestic Violence Helpline}

Freephone 08082000247

www.nationaldomesticviolencehelpline.org.uk

A service for women experiencing domestic violence, their family, friends, colleagues and others calling on their behalf. It is run in partnership between Women's Aid and Refuge. Callers may first of all hear an answerphone message before speaking to a person.

Men's Advice Line Freephone

08088010327 - Days and times of phone support vary.

www.mensadviceline.org .uk/mensadvice.php

A confidential helpline for all men experiencing domestic violence by a current or ex-partner. This includes all men - in heterosexual or same-sex relationships. Offers emotional support, practical advice and information on a wide range of services for further help and support.

Respect Phoneline Freephone

08088024040 Days and times of phone support vary.

www.respectphoneline.org.uk

A confidential helpline for people who are abusive and/or violent towards their partners. Offers information and advice to support perpetrators to stop their violence and change their abusive behaviours. 
Table 1.

\begin{tabular}{|c|c|c|c|}
\hline Physical & Gynaecological/reproductive & Psychosocial & Situational \\
\hline Chronic gastrointestinal symptoms & Chronic pelvic pain & Anxiety & $\begin{array}{l}\text { Frequent healthcare service use } \\
\text { and/or hospital admissions }\end{array}$ \\
\hline Chronic diarrhoea & Sexual dysfunction & Depression & $\begin{array}{l}\text { Frequent/high-level medication } \\
\text { use }\end{array}$ \\
\hline Chronic abdominal pain & $\begin{array}{l}\text { Vaginal bleeding (especially } \\
\text { repeated cases) }\end{array}$ & Eating disorders & Abuse of a child in the family \\
\hline Chronic back pain & $\begin{array}{l}\text { Frequent bladder or kidney } \\
\text { infections }\end{array}$ & Panic disorders & Delays in seeking treatment \\
\hline Chronic headaches & Sexually transmitted infections & Post-traumatic stress disorder & $\begin{array}{l}\text { Not following through with } \\
\text { treatment and/or appointments }\end{array}$ \\
\hline $\begin{array}{l}\text { Other chronic pain, especially } \\
\text { where unexplained }\end{array}$ & $\begin{array}{l}\text { Multiple unintended } \\
\text { pregnancies/terminations }\end{array}$ & Sleep disorders & $\begin{array}{l}\text { Inconsistent, implausible or vague } \\
\text { explanation of injuries }\end{array}$ \\
\hline Unexplained hearing loss & Miscarriages & Somatoform disorders & $\begin{array}{l}\text { Partner who is intrusive or over } \\
\text { attentive in consultations }\end{array}$ \\
\hline $\begin{array}{l}\text { Injuries, especially to head/neck or } \\
\text { multiple regions }\end{array}$ & Delayed prenatal care & Alcohol of other substance misuse & Social isolation \\
\hline Bruises in various stages of healing & Low infant birth weight & Suicide ideation or attempts & $\begin{array}{l}\text { Recent separation of divorce from } \\
\text { (ex)partner }\end{array}$ \\
\hline Lethargy & & self-harm & \\
\hline
\end{tabular}

Table 1 is take from another publication. \\page 54, Valpied, J., \& Hegarty,

K. (2015). Intimate partner abuse: identifying, caring for and helping women in healthcare settings. Women's Health (London, England), 11(1),

51-63. http://doi.org/10.2217/whe.14.59

journal details:

Women's Health - http://journals.sagepub.com/home/whe

Author contact details:

Jodie Valpied - jvalpied@unimelb.edu.au

Kelsey Hegarty - k.hegarty@unimelb.edu.au

I consent to substitution if appropriate. 